\title{
Compliance with a three-day course of artesunate-mefloquine combination and baseline anti-malarial treatment in an area of Thailand with highly multidrug resistant falciparum malaria
}

Kanungnit Congpuong ${ }^{1}$, Pongwit Bualombai ${ }^{1}$, Vick Banmairuroi ${ }^{2}$, Kesara Na-Bangchang ${ }^{2 *}$

\begin{abstract}
Background: Artemisinin-based combination therapy (ACT) is presently recommended by the World Health Organization as first-line treatment for uncomplicated Plasmodium falciparum malaria in several countries, as a mean of prolonging the effectiveness of first-line malaria treatment regimens. A three-day course of artesunatemefloquine ( $4 \mathrm{mg} / \mathrm{kg}$ body weight once daily for three consecutive days, plus 15 and $10 \mathrm{mg} / \mathrm{kg}$ body weight mefloquine on the first and second days) has been adopted by Malaria Control Programme of Thailand as first-line treatment for uncomplicated falciparum malaria all over the country since 2008. The gametocytocydal anti-malarial drug primaquine is administered at the dose of $30 \mathrm{mg}(0.6 \mathrm{mg} / \mathrm{kg})$ on the last day. The aim of the present study was to assess patient compliance of this combination regimen when applied to field condition.
\end{abstract}

Methods: A total of 240 patients (196 males and 44 females) who were attending the malaria clinics in Mae-Sot, Tak Province and presenting with symptomatic acute uncomplicated falciparum malaria, with no reappearance of Plasmodium vivax parasitaemia during follow-up were included into the study. The first dose of the treatment was given to the patients under direct supervision. All patients were given the medication for self-treatment at home and were requested to come back for follow-up on day 3 of the initial treatment. Baseline (day 0) and day 3 whole blood mefloquine and plasma primaquine concentrations were determined by high performance liquid chromatography.

Results: Two patients had recrudescence on days 28 and 35. The Kaplan-Meier estimate of the 42-day efficacy rate of this combination regimen was $99.2 \%$ (238/240). Based on whole blood mefloquine and plasma primaquine concentrations on day 3 of the initial treatment, compliance with mefloquine and primaquine in this three-day artesunate-mefloquine combination regimen were 96.3\% (207/215), and 98.5\% (197/200), respectively. Baseline mefloquine and primaquine levels were observed in 24 and 16\% of the patients.

Conclusion: The current first-line treatment and a three-day combination regimen of artesunate-mefloquine provides excellent patient compliance with good efficacy and tolerability in the treatment of highly multidrug resistance falciparum malaria. Previous treatment with mefloquine and primaquine were common in this area.

\section{Background}

Malaria chemotherapy is under constant threat from the emergence and spread of multidrug resistance of Plasmodium falciparum. Resistance has been observed to

\footnotetext{
* Correspondence: kesaratmu@yahoo.com

${ }^{2}$ Graduate Programme in Biomedical Sciences, Faculty of Allied Health Sciences, Thammasat University (Rangsit Campus), Paholyothin Road, Klong Luang District, Pathumtanee 12121, Thailand
}

almost all currently used anti-malarials. The extensive deployment of anti-malarial drugs in the past fifty years has provided a remarkable selection pressure on malaria parasites to evolve resistance mechanisms. Due to the high resistance level of $P$. falciparum to the most affordable drugs, such as chloroquine and sulphadoxine-pyrimethamine, together with high recrudescence rates with monotherapy with artemisinin derivatives, artemisinin- 
based combination therapy (ACT) is presently recommended by the World Health Organization as first-line treatment for uncomplicated $P$. falciparum malaria in several countries as a mean of prolonging the effectiveness of first-line malaria treatment regimens [1-4]. Artemisinin derivatives are combined with one of several longer-acting drugs, i.e., mefloquine, amodiaquine, sulphadoxine-pyrimethamine, lumefantrine, and piperaquine, which permit elimination of the residual malarial parasites. Among the ACT regimens, the combination of artesunate with mefloquine has remained a highly successful therapeutic regimen in regions habouring the most resistant isolates worldwide particularly in Southeast Asian coutries, such as Thailand and Cambodia [5-9]. It is effective and provides reliably rapid response. The pharmacokinetic advantage of the combination of artesunate with mefloquine is the long half-life of mefloquine (14-21 days), which will eradicate residual parasites remaining from the potent, but short, action of artesunate [10]. In addition, artesunate reduces gametocyte carriage and provides mutual protection for mefloquine against the increased level and spread of resistance [11]. A short course of two or three days is effective and provide reliably rapid therapeutic responses.

In Thailand, where multidrug resistant $P$. falciparum is at high level, the National Malaria Control Programme has adopted artesunate in combination with mefloquine as first-line treatment for uncomplicated falciparum malaria since 1995. The first combination regimen applied initially only in highly mefloquine resistance areas (Tak, Kanchanaburi, Chantaburi, Trat and Mae Hong Son Provinces) was a two-day course of $300 \mathrm{mg}(6 \mathrm{mg} / \mathrm{kg}$ body weight) artesunate given concurrently on the first day with $750 \mathrm{mg}(15 \mathrm{mg} / \mathrm{kg}$ body weight) mefloquine, followed by $500 \mathrm{mg}(10 \mathrm{mg} / \mathrm{kg}$ body weight) mefloquine at six to eight hours apart, then $300 \mathrm{mg}$ artesunate on the second day. In 2004, this combination regimen was adopted to all highly mefloquine resistance areas througout the country, whereas in the low to intermediate resistance areas, the dose of mefloquine was reduced to only a single dose of $750 \mathrm{mg}$ on the first day. Recently in 2008, the combination regimen at the same total dose of $600 \mathrm{mg}$ artesunate and $1,250 \mathrm{mg}$ mefloquine (given as two split doses of 750 and $500 \mathrm{mg}$ ), but with a prolonged duration of three days has been implemented all over the country. The gametocytocydal anti-malarial drug primaquine is administered at the dose of $30 \mathrm{mg}(0.6 \mathrm{mg} / \mathrm{kg})$ on the last day. It is believed that this regimen will improve the cure rate and delay anti-malarial drug resistance. The concern is however, patient compliance when applied to field condition. The main purpose of the present study was to investigate patient compliance of the current three-day course of artesunate-mefloquine as first-line treatment for uncomplicated falciparum malaria in Thailand.

\section{Methods}

The study was conducted at malaria clinics, Tak Provinces, during March 2008 - February 2009. Malaria is a serious imported medical problem in this area with a peak incidence during May-August and November-January of each year. Most patients are adult males and approximately $55 \%$ are caused by P. falciparum [12]. The study was approved by the Ethics Committee of the Departement of Disease Control, Ministry of Public Health of Thailand.

A total of 240 patients (196 males and 44 females) presenting with symptomatic acute uncomplicated falciparum malaria (asexual form parasitaemia over 1,000 per microliter blood), who had no history of liver and kidney disease and no previous anti-malarial treatment during the previous four weeks (based on a questionnaire interview), and with no reappearance of P.vivax parasitaemia during follow-up were recruited into this study. Median (range) values for age and body weight of the patients were 27(4-69) years and 52(18-65) kg, respectively. The study was conducted under the Monitoring Programme for Antimalarial Drug Resistance of the Ministry of Public Health of Thailand. All of the 240 cases were selected based on their residential areas which would have facilitated the complete follow up. Written informed consents were obtained from all patients before study participation.

Prior to treatment (day 0$)$, blood sample $(3 \mathrm{ml})$ was taken from all patients for determination of mefloquine and primaquine concentrations. Patients were treated with a three-day combination regimen of artesunate and mefloquine. The initial dose of $4 \mathrm{mg} / \mathrm{kg}$ body weight artesunate $(200 \mathrm{mg}, 4$ tablets of $50 \mathrm{mg}$ artesunate, Atlantic Pharmaceutical Company, Thailand) and 15 $\mathrm{mg} / \mathrm{kg}$ mefloquine $(750 \mathrm{mg}$, three tablets of $250 \mathrm{mg}$ mefloquine; Atlantic Pharmaceutical Company, Thailand) were given on the first day (dy 0). Then patients were given artesunate and mefloquine tablets for selftreatment at home. The dose regimen on day 2 was 4 $\mathrm{mg} / \mathrm{kg}$ body weight artesunate $(200 \mathrm{mg}, 4$ tablets of 50 $\mathrm{mg}$ artesunate) and $10 \mathrm{mg} / \mathrm{kg}$ body weight mefloquine (500 mg, 2 tablets of $250 \mathrm{mg}$ mefloquine). On day 3, artesunate at the dose of $4 \mathrm{mg} / \mathrm{kg}$ body weight was given with $0.6 \mathrm{mg} / \mathrm{kg}$ body weight primaquine (2 tablets of $15 \mathrm{mg}$ primaquine; Government Pharmaceutical Organization of Thailand). On day 0 , the first dose of the treatment (four tablets of artesunate and three tablets of mefloquine) was given under direct supervision and patient was observed for 30 minutes. If patient vomits within 30 minute, the drug dosages were 
repeated. When necessary, symptomatic treatment with antipyretic paracetamol, and anti-emetic dimenhydrinate (Dramamine ${ }^{\mathrm{TM}}$ ) was administered.

Patients were requested to return for follow-up in the morning of the third day of treatment (day 3 ), and on days $7,14,21,28$ and 42 or at any time if fever or symptoms suggestive of malaria developed. At each visit, a parasite count was performed on a Giemsa-stained blood film, and a detailed questionnaire for general symptoms was recorded. Blood samples were taken (3 $\mathrm{ml}$ ) for determination of mefloquine and primaquine concentrations on day 3 . Whole blood $(1 \mathrm{ml})$ and plasma $(1 \mathrm{ml})$ samples were stored at $-20^{\circ} \mathrm{C}$ immediately for the analysis of mefloquine and primaquine.

Patients failing to respond to the three-day regimen of artesunate-mefloquine were treated with the second-line treatment for uncomplicated falciparum malaria (quinine plus doxycycline given for seven days). Those who developed Plasmodium vivax malaria in their peripheral blood during the follow-up periods were treated with $300 \mathrm{mg}$ (base) of chloroquine to suppress symptoms and a full course of treatment was given at the end of the study period (chloroquine 1,500 mg given over $48 \mathrm{~h}$, followed by $15 \mathrm{mg}$ (base) of primaquine daily for 14 days) and excluded from data analysis.

The clinical outcome of a three-day course of artesunate-mefloquine was evaluated in the group of patients who completed the 42-day follow-up period. The classification of treatment outcomes was based on an assessment of the parasitological and clinical outcome of anti-malarial treatment according to the latest guidelines of WHO. Accordingly, all patients were classified as having an Early Treatment Failure, a Late Clinical Failure, a Late Parasitological Failure, or an Adequate Clinical and Parasitological Response [13]. Patient compliance to treatment medication was defined as his/her reliability in using an exact prescribed medication, together with the levels of the drug taken within the acceptable limits. With the help of a structured questionnaire, patients were interviewed to obtain information on the number of artesunate, mefloquine and primaquine tablets taken. Compliance to the treatment regimen was assessed using Box and Whisker plot by identifying the outlier whole blood mefloquine and plasma primaquine concentrations on day 3 of the initial treatment (1.5-3 box length apart from upper or lower limit line). Mefloquine blood concentrations were measured by high performance liquid chromatography with UV-detection (HPLC-UV) according to the method of Kangwang et $a l$, with quantification limit of $3 \mathrm{ng} / \mathrm{ml}$ [14]. Primaquine plasma concentrations were measured by high performance liquid chromatography with UV-detection
(HPLC-UV) according to the method of Na-Bangchang et al, with quantification limit of $1 \mathrm{ng} / \mathrm{ml}$ [15].

\section{Results}

All patients had a rapid initial response to treatment with parasites cleared from peripheral blood within 3 days of an initial dose of artesunate and mefloquine. All patients completed the 42 day follow-up period. Two patients had recrudescence on day 28 and 35 . The Kaplan-Meier estimate of the 42-day efficacy rate was 99.2\% (95\% CI 99.0-99.8). No serious adverse event (SAE) was reported during the study. Many adverse events (AE) most likely related to the underlying malaria disease such as headache, muscle pain and anorexia. These symptoms disappeared by day 2 or day 3 after the treatment. Based on questionnaire interview, full compliance of $100 \%$ was obtained.

\section{Mefloquine concentrations}

Of the 215 patients whose mefloquine concentrations were measured, 163 (75.8\%) had undetectable baseline mefloquine level, whereas 15 (7.0\%), 24 (11.6\%), and 13 (6.0\%) had concentrations of less than 100 , between 100 and 500 , and more than $500 \mathrm{ng} / \mathrm{ml}$, respectively [median (range):42 $(0-2,424) \mathrm{ng} / \mathrm{ml}$. Since mefloquine is a long half-life drug (14-21 days in patients), the decrease in the concentrations within three days is insignificant and, therefore, day 3 concentrations in patients who had measurable baseline concentrations were estimated by subtraction of baseline concentrations from the measured day 3 concentrations. Figure 1 represents Box and Whisker plot of whole blood mefloquine concentrations on day 3 in 215 cases. The upper, mid and lower lines which represent $1^{\text {st }}, 2^{\text {nd }}$ and $3^{\text {rd }}$ quatiles were $1,716,2,359$, and $3,059 \mathrm{ng} / \mathrm{ml}$, respectively. Median (range) concentrations on day 3 were $2,359(27-10,965) \mathrm{ng} / \mathrm{ml}$, with a $95 \%$ confidence interval of $1,977-2,353 \mathrm{ng} / \mathrm{ml}$. There were 10 patients with outlier mefloquine concentrations (1.5-3 box length apart from the upper or lower limit line). Two had concentrations above the upper limit $(10,000 \mathrm{ng} / \mathrm{ml})$, 7 had concentrations below the lower limit $(27,90,141$, $172,215,247,695 \mathrm{ng} / \mathrm{ml}$ ), and one had undetectable level of mefloquine (lower than quantification limit). Based on mefloquine concentrations on day 3 with exclusion of pharmacokinetic factor, complaince with mefloquine in this three-day artesunate-mefloquine combination regimen was $96.3 \%(207 / 215)$.

\section{Primaquine concentrations}

Of the 214 patients whose primaquine concentrations were measured, $180(84.1 \%)$ had undetectable baseline primaquine level, whereas 29 (13.6\%), 4 (1.9\%), and 1 $(0.5 \%)$ had concentrations of less than 100 , between 100 


\section{Box and Whisker Plot}

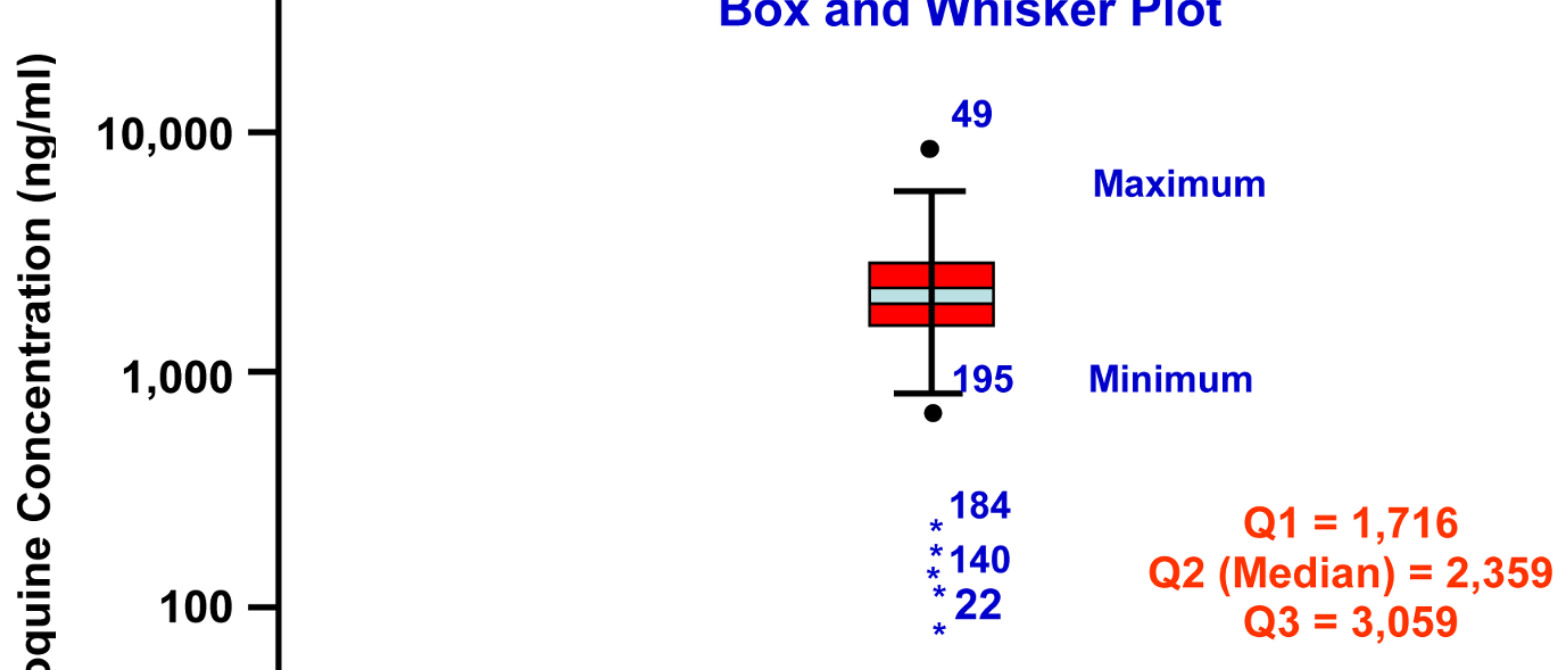

\section{Log MQ day 2}

Figure 1 Box and Whisker plot of whole blood mefloquine concentrations on day $\mathbf{3}$ after the initial treatment. Median, $1^{\text {st }}$ and $3^{\text {rd }}$ quatiles $=2,359,1,716$ and 3,059 ng/ml, respectively. Each individual dots represents the case with outlier concentration below or above 1.5-3 box length.

and 500, and more than $500 \mathrm{ng} / \mathrm{ml}$, respectively [median (range): $0(0-1,662) \mathrm{ng} / \mathrm{ml}]$. Figure 2 represents Box and Whisker plot of plasma primaquine concentrations on day 3 in 200 cases. The upper, mid and lower lines which represent $1^{\text {st }}, 2^{\text {nd }}$ and $3^{\text {rd }}$ quatiles were 1,716 , 2,359, and 3,059 $\mathrm{ng} / \mathrm{ml}$, respectively. Median (range) concentrations on day 3 were $89(6-640) \mathrm{ng} / \mathrm{ml}$, with a $95 \%$ confidence interval of 75-106 $\mathrm{ng} / \mathrm{ml}$. There was no patient with outlier primaquine concentrations, but undetecable concentration was observed in three cases. Whole blood mefloquine concentrations in these cases were as high as 2,669, 2,964 and 6,703 ng/ml. Based on primaquine concentrations on day 3 with exclusion of the pharmacokinetic factor, compliance with primaquine in this three-day artesunate-mefloquine combination regimen was $98.5 \%(197 / 200)$. There was no correlation between the pre-treatment concentrations of mefloquine and primaquine found in this study.

\section{Discussion}

Mefloquine was introduced first as a single-dose therapy for falciparum malaria in Thailand in 1984, but initial high cure rates were not sustained. In a proposition to halt the loss of anti-malarial monotherapies to resistance in rapid succession, the strategy of ACT with mefloquine was developed and was adopted in Thailand in 1994. The current regimen of a three-day combination of artesunate-mefloquine given in total adult dose of $600 \mathrm{mg}$ (12 mg/kg body weight) artesunate and 1,250 $\mathrm{mg}$ ( $25 \mathrm{mg} / \mathrm{kg}$ body weight) mefloquine has been implemented by the Bureau of Vector Borne Disease, Department of Disease Control, Ministry of Public Health for the treatment of acute uncomplicated falciaprum malaria since 2008. The main objective was to obtain high cure rate of approaching $100 \%$ to prevent the spread of drug resistance. Prior to 2008, the same total dose of artesunate-mefloquine was given but as a shorter course of two days and two split doses of mefloquine $(1,250$ and $750 \mathrm{mg})$ given on the same day at 6-8 hours apart instead of two separate days as the current regimen. With the current regimen, in addition to the achievement of high cure rate, the incidence of vomiting due to high dose mefloquine and thus treatment failure is expected to be reduced. Absorption of mefloquine in 


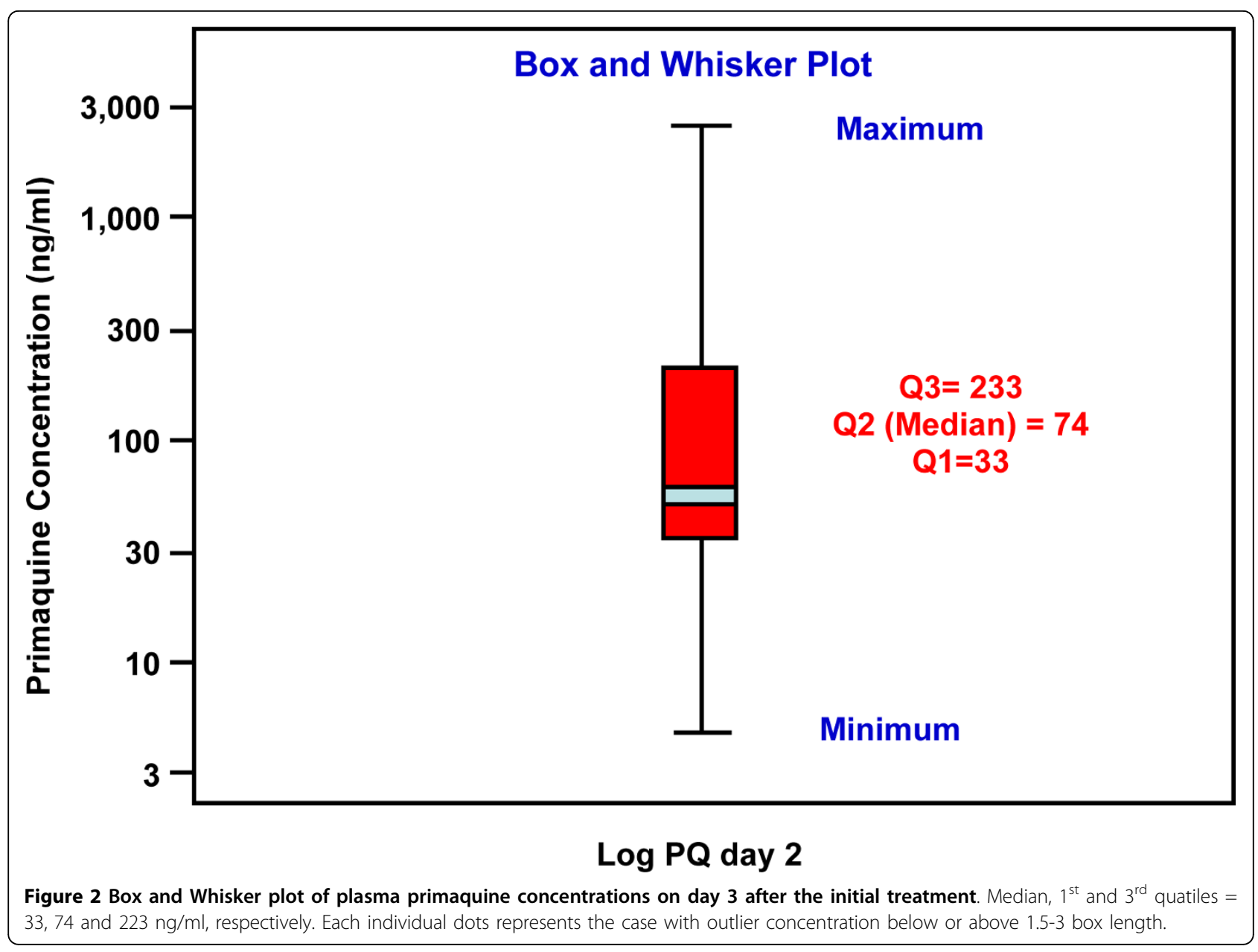

malaria patients is dose limited and is reduced in the acute phase of illness. Splitting the dose of $25 \mathrm{mg} / \mathrm{kg}$ mefloquine improves mefloquine absorption and bioavailability, and thus and the therapeutic response in the treatment of acute falciparum malaria [16-18].

In the present study, a good initial response was observed in all patients where parasitaemia was cleared within three days after the initial dose of artesunate and mefloquine. The present combination regimen of artesunate-mefloquine was shown to improve the cure rate from approximately $87 \%$ with the 2 day course to $96.3 \%$ in the same study area (Tak province) during the year 2001 to 2002 [7]. There were only two cases with treatment failure (cure rate $99.2 \%$ ) on day 28 , and 35 of treatment. It appears that the cure of this combination is still retained after eight years of its use (Ministry of publc Health, unpublished data). The concern about this three-day course is patient compliance when adopted as a public health policy. The aim of the present study was to assess the patient compliance of the current threeday course of artesunate-mefloquine when applied to field condition. As the combination is not a fixed dose regimen, assessment of blood concentration of only one combination partner, i.e. mefloquine with long half-life of 14-21 days [19] may not reflect the real full compliance of the combination regimen. Furthermore, since the half-lives of artesunate and its active plasma metabolite (dihydroartemisinin) are very short (0.5-2 hr), the drug would have been cleared from blood before 24 hours until patients returned for follow-up on the third day of treatment (day 3). Apart from mefloquine, plasma concentrations of primaquine on day 3 was, therefore, also used as a marker of patient's adherence to the three-day regimen with the assumption that if patients took primaquine tablets, it was likely that they would have also taken artesunate tablets on the second and third day. Several methods have been applied for monitoring of compliance to drug treatment particularly in the treatment of chronic diseases. These included clinical judgement of physician, patient self report, clinical response, biochemical measures, pill counts, pharmacy records, electronic medication monitoring devices and measuring of drug concentrations in blood or plasma [20-22]. Most methods except the last one suffer from 
their subjective evaluation. Measurement of anti-malarial drug concentrations in blood has been applied satisfactorily for monitoring of patient compliance to a 2 day combination regimen of artemether-mefloquine when adopted to field application [23]. In another case, measurement of drug other than the anti-malarial itself, e.g. low dose phenobarbital, than the has been applied for monitoring compliance to short course treatment with anti-malarial regimens (5 day course of artesunate and 7 day course of the combination quinine-tetracycline) [24]. The concentrations of artesunate and mefloquine on day 3 (about 24 hours after the last dose of mefloquine and primaquine on day 2) were selected as a time point for monioring the levels of both drugs. Mefloquine is a long half-life drug, therefore, whole blood mefloquine levels on day 3 after the initial treatment could be applied for monitoring of compliance to this combination regimen with good accuracy. Based on mefloquine and primaquine concentrations on day 3 after the intial treatment, patient compliance of as high as $96-98 \%$ was achieved when excluding the pharmacokinetic factor due to poor and variable drug absorption in some cases. It is noted however that patients realized that they were participating in a study and may significantly influenced their behaviour (i.e. better compliance). Using the questionnaire interview as a tool to evaluate compliance to the dose regimen, full compliance of $100 \%$ was obtained, which means that about $2-4 \%$ of non-compliance was undetected by this method. One case with undetectable mefloquine level on day 3 could be definitely classify as non-compliance. The low levels of mefloquine in the seven cases could be due either to non-compliance to the second dose of mefloquine or impaired drug absorption in each individual as none vomited within the first hour. In our previous study, patient compliance with a two-day course of artemether-mefloquine (an initial dose of $300 \mathrm{mg}$ artemether on the first day, followed by 750 and $500 \mathrm{mg}$ meflouine given on the second day at 4-6 hours apart) was investigated in the same area of the country. Median (range) whole blood mefloquine concentrations following the split doses were determined on the third day ( 1 day after the initial dose of mefloquine) was $2,262(1,198-3,241) \mathrm{ng} / \mathrm{ml}$. This is considered relatively low when compared with the concentrations observed after three days of an initial dose of mefloquine [median (range) of $2359(27-10,965) \mathrm{ng} / \mathrm{ml}$. For primaquine on the other hand, plasma concentration on day 3 may not be absolutely a suitable marker for monitoring of compliance to this combination regimen in this field setting as the half-life of primaquine is relatively short (3.7-9.5 hr) [15]. It has been reported that plasma concentration of primaquine at $25 \mathrm{hr}$ after a single oral dose of primaqune is only approximately 10 $15 \%$ of the $C_{\max }$ [15]. The case with undetectable primaquine concentration could be due to pharmacokinetic factors (impaired absorption and/or rapid clearance) and/or genuine non-compliance. Full compliance of approaching $100 \%$ with this short course regimen is considered excellent when comparing with compliance to long treatment courses of other regimens, such as a seven-day course of quinine-tetracycine, where prolonged drug administration or a relatively high incidence of cinchonism contributes to about $71.7 \%$ compliance in the field trials [25]. This excellent compliance to the treatment regimen may also be due to reduced incidence of adverse effects from mefloquine with the split dose. A simple pre-packaging system and proper counselling could improve compliance with anti-malarial drug treatment $[6,26,27]$. Co-formulation of the drugs reduces the pill burden and more importantly, eliminates the possibility of patients taking only one component of the combination. In one study, pre-packaging anti-malarial drugs have been shown to improve compliance by approximately $20 \%$ in both adults and children [27]. In addition, there were $50 \%$ reductions in cost of patients, waiting time at dispensaries and drug wastage at facilities. A new fixed-dose co-formulation of artesunate-mefloquine has been launched by Drugs for Neglected Diseases Initiative (DNDi), which decreases the risk of resistance due to compliance factor [28]. Nevertheless, this strategy may have limitation with regard to practicality of dose adjustment.

It is interesting to note that 24.2 and $15.9 \%$ of patients had mefloquine and primaquine levels at baseline pretreatment. Seven\% had baseline mefloquine concentrations less than $100 \mathrm{ng} / \mathrm{ml}, 11.6 \%$ had concentrations between 100 and $500 \mathrm{ng} / \mathrm{ml}$, and $13 \%$ had concentrations greater than $500 \mathrm{ng} / \mathrm{ml}$. This implies that patients may have received previous treatment with mefloquine longer than 35-48, between $35-48$, and within 14 days, respectively [29]. In one of our previous study, it was observed that 10.2, 11.5, 6.0 and $1.1 \%$ had baseline whole blood mefloquine concentrations of $<100,100$ $500,>500-1,000$, and $>1,000 \mathrm{ng} / \mathrm{ml}$, respectlvely [30]. The lower incidence of observed baseline primaquine level could be explained by the short half-life of primaquine [15]. High incidence of baseline levels in this patient population indicates the high rate of malaria transmission in this area and/or drug resistance. Patients may have received treatment with artesunate-mefloquine treatment with or without primaquine (as a gametocytocide for falciparum malaria or as antirelapse for vivax malaria) from other health services nearby or from illegal anti-malarial drugs available in the markets for the current or previous malaria episode. There has been no data on the adherence to the 14-day course of primaquine for the treatment of vivax malaria, especially primaquine for the treatment of vivax malaria. There was 
no data on the adherence to the 14 day course of primaquine for the treatment of vivax malaria. Based on the prevalence of primaquine levels on admission of greater than $15 \%$, and when considering the short half-life of this drug, this would suggest that some may have received previous treatment with primaquine within a day before participation in the study. This is of concern as accumulated high level of mefloquine may aggravate high incidence of adverse effects especially the serious neuropsychiatric effect. Based on patients' interview, none received previous treatment with any anti-malarial drug. Measurement of drug levels are, therefore, good confirmation of previous anti-malarial treatment.

\section{Conclusion}

The current first-line treatment three-day combination regimen of artesunate-mefloquine provides excellent patient compliance with good efficacy and tolerability in the treatment of multidrug resistance falciparum malaria in field setting. Previous treatment with mefloquine and primaquine was common in this area. The results obatined are useful for the malaria control programme of Thailand as baseline data for optimization of treatment regimen for uncomplicated falciparum malaria.

\section{Acknowledgements}

The study was supported by the Department of Disease Control, Ministry of Public Health, and The Commission on Higher Education, Ministry of Education of Thailand. Kanungnit Congpoung and Kesara Na-Bangchang were supported by the Ministry of Public Health, and The Commission on Higher Education, Ministry of Education of Thailand.

\section{Author details}

${ }^{1}$ Bureau of Vector Borne Disease, Department of Disease Control, Ministry of Public Health, Muang District, Nonthaburi, Thailand. ${ }^{2}$ Graduate Programme in Biomedical Sciences, Faculty of Allied Health Sciences, Thammasat University (Rangsit Campus), Paholyothin Road, Klong Luang District, Pathumtanee 12121, Thailand.

\section{Authors' contributions}

KC participated in the design of the study and performed the statistical analysis. PB conceived of the study, and participated in study coordination. VM carried out the measurement of drug concentrations. KN partcipated in the design of the study, data analysis and drafted the manuscript. All authors read and approved the final manuscript.

\section{Competing interests}

The authors declare that they have no competing interests.

Received: 26 September 2009

Accepted: 4 February 2010 Published: 4 February 2010

\section{References}

1. Price RN, Nosten F, Luxemburger C, ter Kuile FO, Paiphun L, Chongsuphajaisiddhi T, White NJ: Effects of artemisinin derivatives on malaria transmissibility. Lancet 1996, 347:1654-1658.

2. Nosten $F$, van Vugt $M$, Price $R$, Luxemburger $C$, Thway $K L$, Brockman $A$, McGready R, ter Kuile F, Looareesuwan S, White NJ: Effects of artesunatemefloquine combination on incidence of Plasmodium falciparum malaria and mefloquine resistance in estern Thailand: a prospective study. Lancet 2000, 356:297-302.
3. Muheki C, Mclntyre D, Barnes Kl: Artemisinin-based combination therapy reduces expenditure on malaria treatment in KwaZulu Natal, South Africa. Trop Med Int Health 2004, 9:959-966.

4. Barnes KI, Durrheim DN, Little F, Jackson A, Mehta U, Allen E, Dlamini SS, Tsoka J, Bredenkamp B, Mthembu DJ, White NJ, Sharp BL: Effect of artemether-lumefantrine policy and improved vector control on malaria burden in KwaZulu-Ntal, South Africa. PLoS Med 2005, 2:330.

5. Carrara VI, Sirilak S, Thonglairuam J, Rojanawatsirivet C, Proux S, Gilbos V, Brockman A, Ashley EA, McGready R, Krudsood S, Leemingsawat S, Looareesuwan S, Singhasivanon P, White N, Nosten F: Deployment of early diagnosis and mefloquine-artesunate treatment of falciparum malaria in Thailand: the Tak Malaria Initiative. PLoS Med 2006, 3:e183.

6. Ashley EA, Lwin KM, McGready R, Simon WH, Phaiphun L, Proux $S$, Wangseang N, Taylor W, Stepniewska K, Nawamaneerat W, Thwai KL, Barends M, Leowattana W, Olliaro P, Singhasivanon P, White NJ, Nosten F: An open label randomized comparison of mefloquine-artesunate as separate tablets vs. a new co-formulated combination for the treatment of uncomplicated multidrug-resistant falciparum malaria in Thailand. Trop Med Int Health 2006, 11:1653-1660.

7. Hutagalung R, Paiphun L, Ashley EA, McGready R, Brockman A, Thwai KL, Singhasivanon $\mathrm{P}$, Jelinek $\mathrm{T}$, White NJ, Nosten $\mathrm{FH}$ : A randomized trial of artemether-lumefantrine versus mefloquine-artesunate for the treatment of uncomplicated multi-drug resistant Plasmodium falciparum on the western border of Thailand. Malar J 2005, 4:46.

8. McGready R, Brockman A, Cho T, Cho D, van Vugt M, Luxemburger C, Chongsuphajaisiddhi T, White NJ, Nosten F: Randomized comparison of mefloquine-artesunate versus quinine in the treatment of multidrugresistant falciparum malaria in pregnancy. Trans $R$ Soc Trop Med Hyg 2000, 94:689-693.

9. Chanthap L, Tsuyuoka R, Na-Bangchang K, Nivanna N, Suksom D, Sovannarith T, Socheat D: Investigation of bioavailability, pharmacokinetics and safety of new pediatric formulations of artesunate and mefloquine. Southeast Asian J Trop Med Public Health 2005, 36:34-43.

10. Na-Bangchang K, Karbwang J: Current status of malaria chemotherapy and the role of pharmacology in antimalarial drug research and development. Fundam Clin Pharmacol 2009, 23:387-409.

11. Suputtamongkol Y, Chindarat S, Silpasakorn S, Chaikachonpatd S, Lim K, Chanthapakajee K, Kaewkaukul N, Thamlikitkul V: The efficacy of combined mefloquine-artesunate versus mefloquine-primaquine on subsequent development of Plasmodium falciparum gametocytemia. Am J Trop Med Hyg 2003, 68:620-623.

12. Na-Bangchang K, Karbwang J: Current status of malaria chemotherapy and the role of pharmacology in antimalarial drug research and development. Fundam Clin Pharmacol 2009, 23:387-409.

13. World Health Organization: World Malaria Report of a WHO ScientificGroup. World Health Organization, Geneva, Thailand 2008.

14. Karbwang J, Molunto P, Na Bangchang K, Bunnag D: Determination of mefloquine in biological fluids using high performance liquid chromatography. Southeast Asian J Trop Med Public Health 1989, 20:55-60.

15. Na-Bangchang K, Songsaeng W, Thanavibul A, Choroenlarp P, Karbwang J: Pharmacokinetics of primaquine in G6PD deficient and G6PD normal patients with vivax malaria. Trans R Soc Trop Med Hyg 1994, 88:220-222.

16. Price $R$, Simpson JA, Teja-Isavatharm $P$, Than MM, Luxemburger $C$, Heppner DG, Chongsuphajaisiddhi T, Nosten F, White NJ: Pharmacokinetics of mefloquine combined with artesunate in children with acute falciparum malaria. Antimicrob Agents Chemother 1999, 43:341-346.

17. Simpson JA, Aarons $L$, Price R, White NJ: The influence of body weight on the pharmacokinetics of mefloquine. Br J Clin Pharmacol 2002, 53:337-338.

18. Ashley EA, Stepniewska K, Lindegårdh N, McGready R, Hutagalung R, Hae R, Singhasivanon P, White NJ, Nosten F: Population pharmacokinetic assessment of a new regimen of mefloquine used in combination treatment of uncomplicated falciparum malaria. Antimicrob Agents Chemother 2006, 50:2281-2285.

19. Karbwang J, White NJ: Clinical pharmacokinetics of mefloquine. Clin Pharmacokinet 1990, 19:264-279.

20. Claxton AJ, Cramer J, Pierce C: A systematic review of the associations between dose regimens and medication compliance. Clin Ther 2001, 23:1296-1310.

21. Lee JY, Kusek JW, Greene PG: Assessing medication adherence by pill count and electronic monitoring in the African American Study of 
Kidney Disease and Hypertension (AASK) Pilot Study. Am J Hypertens 1996, 9:719-725.

22. Saini SD, Schoenfeld P, Kaulback K, Dubinsky MC: Effect of medication dosing frequency on adherence in chronic diseases. Am J Manag Care 2009, 15:e22-33.

23. Na-Bangchang K, Congpuong K, Sirichaisinthop J, Suprakorb K, Karbwang J: Compliance with a 2 day course of artemether-mefloquine in an area of highly multi-drug resistant Plasmodium falciparum malaria. Br J Clin Pharmacol 1997, 43:639-642.

24. Karbwang J, Fungladda W, Pickard CE, Shires S, Hay A, Feely M: Initial evaluation of low-dose phenobarbital as an indicator of compliance with antimalarial drug treatment. Bull World Health Organ 1998, 76:67-73.

25. Fungladda W, Honrado ER, Thimasarn K, Kitayaporn D, Karbwang J, Kamolratanakul P, Masngammueng R: Compliance with artesunate and quinine + tetracycline treatment of uncomplicated falciparum malaria in Thailand. Bull World Health Organ 1998, 76(Suppl 1):59-66.

26. Lauwo JA, Hombhanje FW, Tulo SP, Maibani G, Bjorge S: Impact of prepackaging antimalarial drugs and counselling on compliance with malaria treatment at Port Moresby General Hospital Adult Outpatient Department. P N G Med J 2006, 49:14-21

27. Drugs for Neglected Disease Initiative. http:///www.dndi.org

28. Yeboah-Antwi K, Gyapong JO, Asare IK, Barnish G, Evans DB, Adjei S: Impact of prepackaging antimalarial drugs on cost to patients and compliance with treatment. Bull World Health Organ 2001, 79:394-399.

29. Karbwang J, Na-Bangchang K, Thanavibul A, Bunnag D, Harinasuta T: Pharmacokinetics of mefloquine in treatment failure. Southeast Asian J Trop Med Public Health 1991, 22:523-526.

30. Congpuong K, Sirtichaisinthop J, Tippawangkosol P, Suprakrob K, NaBangchang K, Tan-ariya P, Karbwang J: Incidence of antimalarial pretreatment and drug sensitivity in vitro in multidrug-resistant Plasmodium falciparum infection in Thailand. Trans R Soc Trop Med Hyg 1998, 92:84-86.

doi:10.1186/1475-2875-9-43

Cite this article as: Congpuong et al:: Compliance with a three-day course of artesunate-mefloquine combination and baseline anti-malarial treatment in an area of Thailand with highly multidrug resistant falciparum malaria. Malaria Journal 2010 9:43.

\section{Submit your next manuscript to BioMed Central and take full advantage of:}

- Convenient online submission

- Thorough peer review

- No space constraints or color figure charges

- Immediate publication on acceptance

- Inclusion in PubMed, CAS, Scopus and Google Scholar

- Research which is freely available for redistribution

Submit your manuscript at www.biomedcentral.com/submit
Biomed Central 